\title{
Ash and ice clouds during the Mt Kelud February 2014 eruption as interpreted from IASI and AVHRR/3 observations
}

\author{
Arve Kylling \\ NILU - Norwegian Institute for Air Research, P.O. Box 100, 2027 Kjeller, Norway \\ Correspondence to: Arve Kylling (arve.kylling@nilu.no)
}

Received: 27 November 2015 - Published in Atmos. Meas. Tech. Discuss.: 28 January 2016

Revised: 22 April 2016 - Accepted: 26 April 2016 - Published: 12 May 2016

\begin{abstract}
During the Mt Kelud February 2014 eruption the ash cloud was detectable on 13-14 February in the infrared with the reverse absorption technique by, for example, the Advanced Very High Resolution Radiometer (AVHRR/3). The Infrared Atmospheric Sounding Interferometer (IASI) observed the ash cloud also on 15 February when AVHRR did not detect any ash signal. The differences between ash detection with AVHRR/3 and IASI are discussed along with the reasons for the differences, supported by radiative transfer modelling. The effect of concurrent ice clouds on the ash detection and the ash signal in the IASI measurements is demonstrated. Specifically, a radiative transfer model is used to simulate IASI spectra with ash-only, with ice cloud only and with both ash and ice clouds. It is shown that modelled IASI spectra with ash and ice clouds reproduce the measured IASI spectra better than ash-only- or ice-only-modelled spectra. The ash and ice modelled spectra that best reproduce the IASI spectra contain about a factor of 12 less ash than the ash-only spectra that come closest to reproducing the measured spectra.
\end{abstract}

\section{Introduction}

During volcanic eruptions large quantities of ash may be ejected high into the atmosphere. The ash may be observed by both UV-visible and infrared (IR) satellite instruments. The ash make volcanic clouds rich on ice-forming nuclei. The dominant volatile in explosive volcanic eruptions is water and for eruptions reaching high and cold altitudes eruption plumes may thus contain ice. Durant et al. (2008) showed that compared to similar meteorological clouds, enhanced ice crystal concentrations and smaller average ice size may be expected in volcanic clouds. However, the "specific chemical and physical properties of volcanic ash particles that could affect their ability to induce ice formation are poorly understood" (Kulkarni et al., 2015).

The first detection of ice in volcanic clouds was reported by Rose et al. (1995) for the 1994 Rabaul eruption. The presence of ice masked the spectral signature of volcanic ash and no silicate nor sulphate signal was seen in the Advanced Very High Resolution Radiometer (AVHRR) data. Rose et al. (2004) gave examples of volcanic eruptions resulting in ice dominant volcanic clouds, clouds where ice is subordinated, and volcanic clouds with sub-equal proportions of ice and ash. They state that "for detection using infrared remote sensing, ice presence in the volcanic cloud interferes with volcanic ash, which means that the simplest detection schemes ( 2 band brightness temperature differencing) may be less sensitive or even ineffective". Guo et al. (2004) reported on the role of ice cloud in the Pinatubo June 1991 volcanic cloud. In addition to a 2 band AVHRR retrieval, they showed a 6 band simultaneous ash, ice and sulfate retrieval using High Resolution Infrared Radiation Sounder/2 (HIRS/2) data. They found that the multispectral IR data from HIRS/2 outperformed the 2 band AVHRR retrieval due to the presence of both ice and ash.

The Infrared Atmospheric Sounding Interferometer (IASI) onboard the Meteorological Operational (MetOp)A, MetOp-B, and MetOp-C satellites, measures infrared radiation with high spectral resolution. As such it has the potential to provide increased information content compared to spectral band instruments such as AVHRR/3, the Moderate Resolution Imaging Spectroradiometer (MODIS), the Spinning Enhanced Visible and InfraRed Imager (SEVIRI) and the Multifunctional Transport Satellite (MSAT) imager. 
IASI is dedicated to operational meteorological soundings of temperature and humidity. It may also be used to detect and measure the amount of a number of trace gases (Clerbaux et al., 2009; Hilton et al., 2011). IASI has been successfully used to detect volcanic ash. In the $800-1200 \mathrm{~cm}^{-1}$ region silicate absorbers exhibit a characteristic "V" shape (see for example Fig. 2 of Clarisse et al., 2010b). DeSouzaMachado et al. (2006) used this characteristic "V" shape to retrieve the IR optical depth of dust storms as recorded by the Atmospheric Infrared Sounder (AIRS). Gangale et al. (2010) used the same spectral signature to detect ash in AIRS data. Their concavity algorithm utilizes the spectral behaviour of the brightness temperature in the $800-1130 \mathrm{~cm}^{-1}$ range to distinguish ash from desert dust and ice and water clouds. They also demonstrated that the concavity increases monotonically with increasing optical depth, thus indicating that concavity may be used to infer particle size and composition. Clarisse et al. (2013) gave an overview of the various methods used for aerosol (and ash) detection from hyperspectral infrared sounders. These methods include feature detection, spectral fitting, distance approaches, singular value decomposition and principal component analysis, and methods utilizing geophysical information.

During an eruption, volcanic ash may be the dominating compound in the atmospheric column viewed by each instrument pixel; however, it is seldom the sole compound, as ice may be present in the volcanic cloud and meteorological clouds may also be present elsewhere in the atmospheric column. Concerning the latter, Maddy et al. (2011) estimated that less than $10 \%$ of the footprints of the Infrared Atmospheric Sounding Interferometer (IASI) are expected to be cloud free. Thus, the radiometric signal measured by IASI during a volcanic eruption may have contributions from meteorological clouds.

The aims of the present study are to (1) investigate the combined impact of ash and water ice clouds on IASI MetOp-A spectra using radiative transfer modelling, and (2) find the combination of ash and ice clouds that best reproduce the spectra measured during the Mt Kelud 2014 eruption. In addition to IASI data, measurements from AVHRR/3, also onboard MetOp-A, are used.

\section{Mt Kelud February 2014 eruption}

Mt Kelud, Indonesia, erupted on 13 February 2014 at 22:50 LT (UT+7). The explosive eruption declined the following days and on 21 Feb the volcano's alert status was downgraded. The eruption was detected in data from several satellite instruments including IR data from the geostationary MTSAT imager using IR channels similar to the AVHRR/3 instrument (Kristiansen et al., 2015). The satellite imagery showed that the ash cloud from the Mt Kelud eruption thinned quickly and after 14 February the ash cloud was no longer visible close to the volcano in IR data using the reverse absorption technique (Kristiansen et al., 2015).

\section{IASI and AVHRR data}

Both the IASI and AVHRR/3 instruments onboard the polar orbiting MetOp-A satellite observed the Mt Kelud 2014 ash cloud.

\subsection{The Advanced Very High Resolution Radiometer (AVHRR/3)}

AVHRR/3 has three solar and three thermal channels and a spatial resolution of $1.1 \mathrm{~km}$ at nadir. The AVHRR/3 thermal channels 4 and 5 are centered at 10.8 and $12.0 \mu \mathrm{m}$, respectively, and may be used for detection of volcanic ash by the reverse absorption technique (Prata, 1989; Wen and Rose, 1994). The brightness temperature difference (BTD) between AVHRR/3 channels 4 and 5 for 14 and 15 February covering Mt Kelud, is shown in the left panels of Figs. 1 and 2. By the reverse absorption technique volcanic-ash-affected pixels are identified by looking for pixels with BTD less than some threshold value, typically set between -0.5 and -1 . As shown by for example Yu et al. (2002), tropospheric water vapour may increase the BTD such that ash clouds are not identified. Yu et al. (2002) devised a scheme for correction for water vapour absorption. Ash shown in their Fig. 8, the correction is largest for pixels with transparent ash cloud and no underlying ice and liquid water clouds. The AVHRR/3 scenes presented in the left panels of Figs. 1 and 2 are inhomogeneous with clouds of variable optical thickness at different altitudes. The presence of scattered high altitude clouds masks the radiation emitted from the surface. Including water vapour absorption correction (not shown) introduces a large number of false positives. It has hence not been included.

For 14 February 2014, 02:53 UTC there is an area between 7 and $10^{\circ} \mathrm{S}$ and $106-110^{\circ} \mathrm{E}$ where $\mathrm{BTD}<-0.5$, left panel Fig. 1. The pixels within this area are thus identified as ash affected. The BTD for 15 February 2014, 02:29-02:35 UTC, is shown in the left panel of Fig. 2. Less than $0.001 \%$ of the pixels in this plot have BTD $<-0.5$ and they are scattered around. Hence, no ash is identified by AVHRR/3 in this image similar to what is reported from MTSAT observations for this date by Kristiansen et al. (2015).

\subsection{The Infrared Atmospheric Sounding Interferometer (IASI)}

IASI covers the spectral range from 645 to $2760 \mathrm{~cm}^{-1}$ $(15.50-3.6 \mu \mathrm{m})$. The spectral resolution varies with wavelength and lies between 0.3 and $0.5 \mathrm{~cm}^{-1}$. The Level $1 \mathrm{C}$ products have spectral resolution of $0.5 \mathrm{~cm}^{-1}$ and are sampled every $0.25 \mathrm{~cm}^{-1}$. This gives a total of 8461 radiance values per spectrum (Clerbaux et al., 2009). For the wavenumber interval exploited here, $700-1250 \mathrm{~cm}^{-1}$, the noise equiv- 

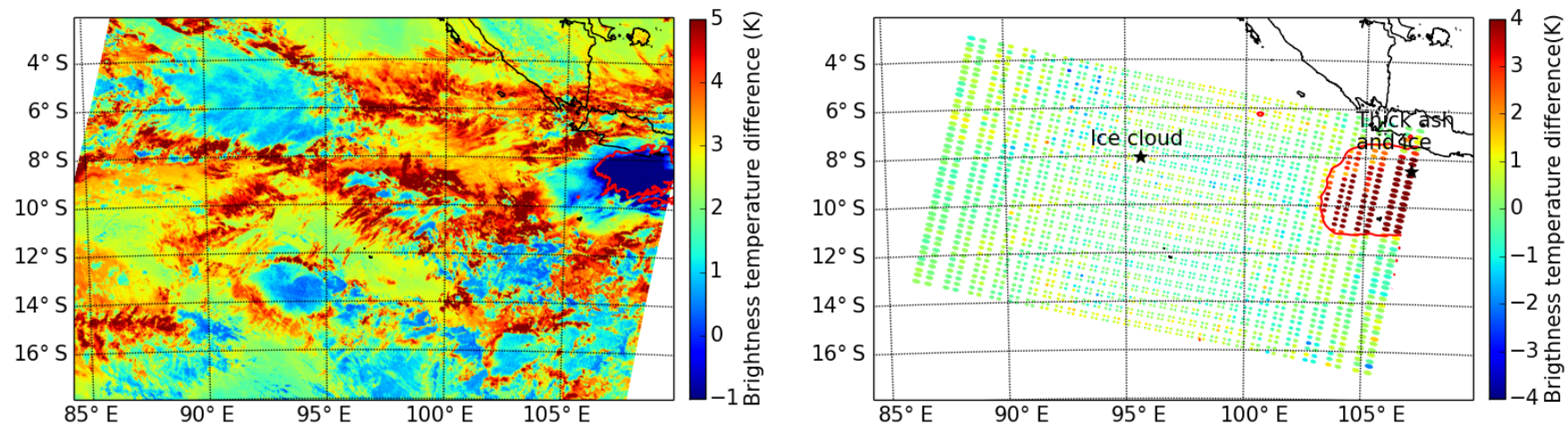

Figure 1. (Left panel) The brightness temperature difference between AVHRR/3 channels 4 and $5\left(\mathrm{BTD}_{\mathrm{A}}=\mathrm{BT}_{4}-\mathrm{BT}_{5}\right)$. The contour line (red) is at $-0.5 \mathrm{~K}$. (Right panel) The $1231.5-1097.25 \mathrm{~cm}^{-1}$ brightness temperature difference from IASI/MetOp-A spectra. The contour line is at $1.5 \mathrm{~K}$. Data from 14 February 2014, 02:53 UTC.
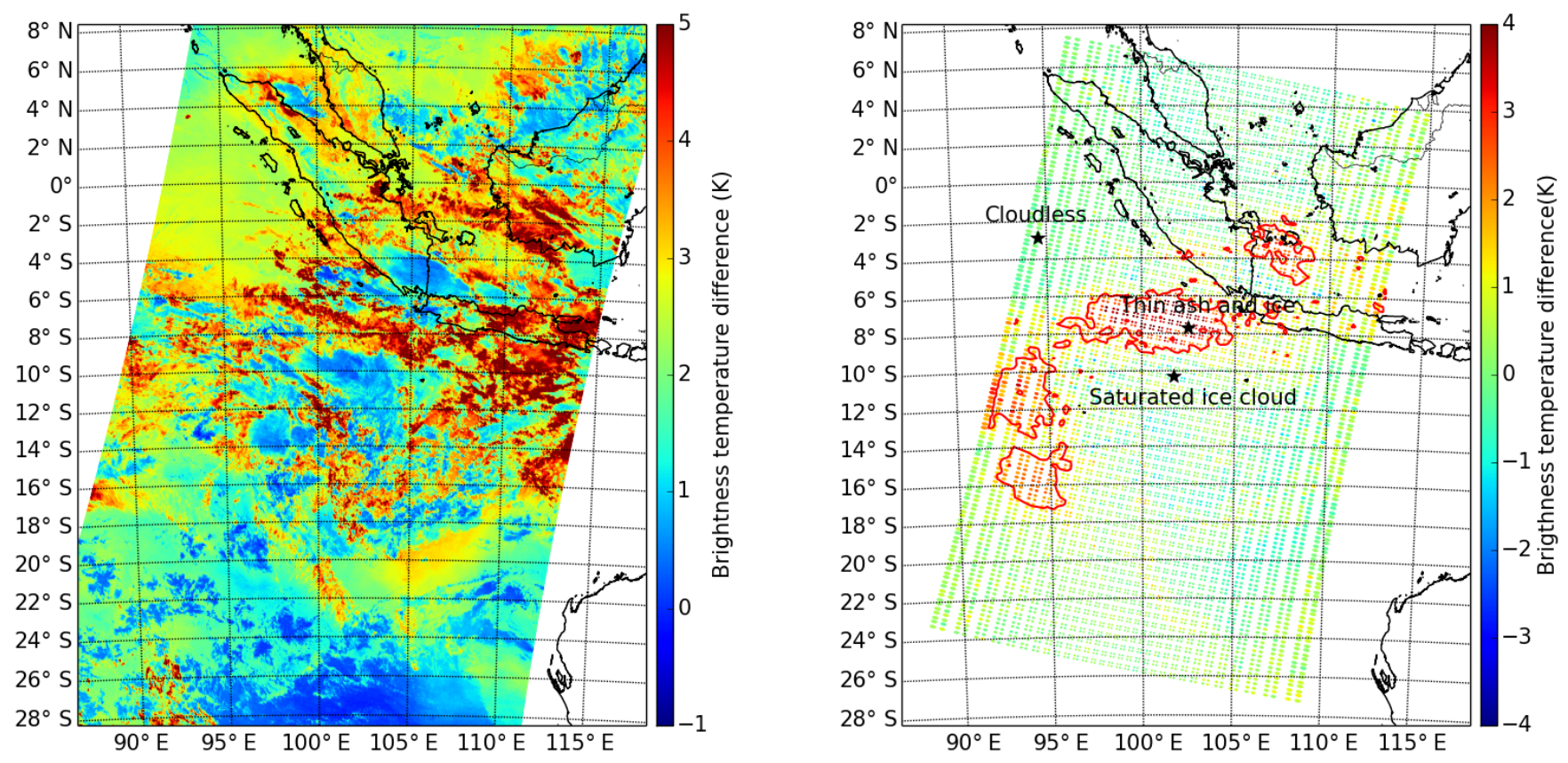

Figure 2. (Left panel) The brightness temperature difference between AVHRR/3 channels 4 and $5\left(\mathrm{BTD}_{\mathrm{A}}=\mathrm{BT}_{4}-\mathrm{BT}_{5}\right)$. $(\mathrm{Right}$ panel) The $1231.5-1097.25 \mathrm{~cm}^{-1}$ brightness temperature difference from IASI/MetOp-A spectra. The contour line is at $1.5 \mathrm{~K}$. Data from $15 \mathrm{February}$ 2014, 02:29-02:35 UTC.

alent temperature difference is less than $0.2 \mathrm{~K}$ (Table 1, Clerbaux et al., 2009). Each spectrum represents a circular footprint with diameter of $12 \mathrm{~km}$ at nadir. At the swath edges the footprint is roughly elliptical with axes of $39 \mathrm{~km}$ (across track) and $20 \mathrm{~km}$ (along track) (Clarisse et al., 2011). The spatial resolution of AVHRR/3 is about $1.1 \mathrm{~km}$. Hence one IASI footprint is covered by approximately 90 AVHRR/3 pixels.

Due to the larger spectral coverage and higher spectral resolution several approaches may be used to detect volcanic ash with IASI (Clarisse et al., 2013). A simple brightness temperature difference scheme defined as the brightness temperature difference between the channels at 1231.5 and $1168 \mathrm{~cm}^{-1}$ was used by Clarisse et al. (2010a). This approach is based on the characteristic "V" shape (see for example Fig. 2 of Clarisse et al., 2010b) of silicate absorbers in the $800-1250 \mathrm{~cm}^{-1}$ region. A pixel is said to contain ash if the brightness temperature is larger than some threshold value, $0.5 \mathrm{~K}$ was used by Clarisse et al. (2010a).

However, the $1168 \mathrm{~cm}^{-1}$ channel may be affected by absorption in the symmetric stretch $v_{1}$ band of $\mathrm{SO}_{2}$ which covers the $1070-1230 \mathrm{~cm}^{-1}$ region, see left panel of Fig. 3. The channel at $1097.25 \mathrm{~cm}^{-1}$ is little affected by $\mathrm{SO}_{2} v_{1}$ absorption and outside the ozone absorption band between 1000 and $1080 \mathrm{~cm}^{-1}$. To estimate the $\mathrm{SO}_{2}$ effect on this channel, radiative transfer simulations (described in further de- 
Table 1. Information pertinent to IASI data shown in Fig. 4. $\mathrm{BTD}_{\mathrm{I}}$ is the brightness temperature difference between the channels at 1231.5 and $1097.25 \mathrm{~cm}^{-1} . \mathrm{BT}_{4}$ is the mean AVHRR channel 4 brightness temperature for the AVHRR pixels covering the IASI footprint, and $\sigma_{\mathrm{BT}}$ the standard deviation. The brigthness temperature difference between the means of AVHRR channels 4 and $5, \mathrm{BTD}_{\mathrm{A}}=\mathrm{BT}_{4}-\mathrm{BT}_{5}$ is given in column 8. AML denotes the ash mass loading, $r_{\mathrm{eff}}$ is the ash particle effective radius, IWC is the ice water content and ICT the ice cloud top height. RMSD is defined in Eq. (1).

\begin{tabular}{|c|c|c|c|c|c|c|c|c|c|c|c|c|c|}
\hline $\begin{array}{l}\text { Day } \\
\text { (dd) }\end{array}$ & $\begin{array}{c}\text { Time } \\
(\mathrm{hhmm})\end{array}$ & $\begin{array}{l}\text { Latitude } \\
\quad\left({ }^{\circ}\right)\end{array}$ & $\begin{array}{c}\text { Longitude } \\
\left({ }^{\circ}\right)\end{array}$ & $\begin{array}{l}\text { BTD }_{\mathrm{I}} \\
(\mathrm{K})\end{array}$ & $\begin{array}{l}\mathrm{BT}_{4} \\
(\mathrm{~K})\end{array}$ & $\begin{array}{c}\sigma_{\mathrm{BT}} 4 \\
(\mathrm{~K})\end{array}$ & $\begin{array}{c}\mathrm{BTD}_{\mathrm{A}} \\
(\mathrm{K})\end{array}$ & $\begin{array}{c}\text { AML } \\
\left(\mathrm{g} \mathrm{m}^{-2}\right)\end{array}$ & $\begin{array}{c}r_{\text {eff }} \\
(\mu \mathrm{m})\end{array}$ & $\begin{array}{c}\text { IWC } \\
\left(\mathrm{g} \mathrm{m}^{-3}\right)\end{array}$ & $\begin{array}{l}\mathrm{ICT} \\
(\mathrm{km})\end{array}$ & $\begin{array}{l}\text { RMSD } \\
(\mathrm{K})\end{array}$ & Comments \\
\hline 14 & 0254 & -8.47211 & 106.89724 & 17.16 & 226.0 & 2.6 & -4.45 & 2.5 & 1.0 & 0.075 & 14.0 & 1.52 & Thick ash and ice \\
\hline 14 & 0254 & -8.02064 & 95.61739 & 0.10 & 272.4 & 8.2 & 3.77 & - & - & 0.03 & 13.0 & 0.92 & Ice cloud \\
\hline 15 & 0232 & -2.82008 & 94.51644 & -0.15 & 294.1 & 0.1 & 2.63 & - & - & 0.001 & 16.0 & 0.59 & Cloudless \\
\hline 15 & 0232 & -7.6605 & 102.47361 & 4.11 & 246.4 & 6.0 & 4.38 & 2.0 & 6.0 & 0.05 & 15.0 & 0.63 & Thin ash and ice \\
\hline 15 & 0232 & -10.28912 & 101.70977 & 0.24 & 202.8 & 1.1 & 0.56 & - & - & 0.2 & 16.0 & 1.39 & Saturated ice cloud \\
\hline
\end{tabular}
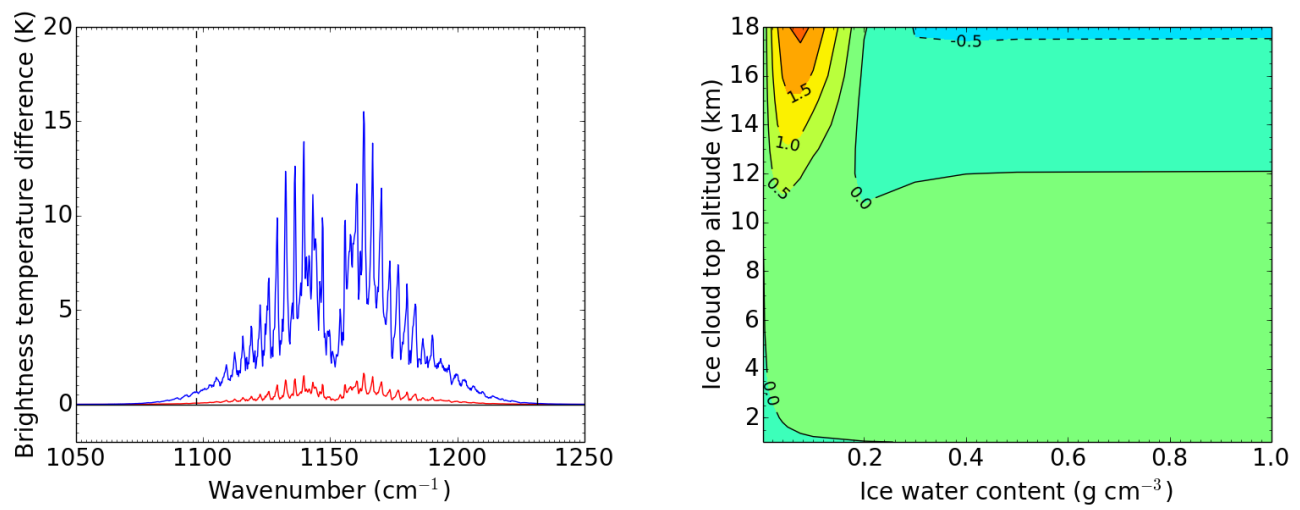

Figure 3. (Left panel) The difference between a spectrum with background $\mathrm{SO}_{2}$ and with a $\mathrm{SO}_{2}$ plume between 17 and $19 \mathrm{~km}$ giving a total column of 10 (100) DU, red (blue) line. The dashed vertical lines locates the 1097.25 and $1231.5 \mathrm{~cm}^{-1}$ channels. (Right panel) The 1231.5-1097.25 $\mathrm{cm}^{-1}$ brightness temperature difference BTD $(\mathrm{K})$ for a horizontal water ice cloud of $1 \mathrm{~km}$ thickness as a function of ice cloud top height and ice water content.

tail in Sect. 4) were made. First a simulation with a background $\mathrm{SO}_{2}$ column of $0.13 \mathrm{DU}$ and no ash were made, giving $\mathrm{BTD}_{\mathrm{I}}=\mathrm{BT}_{1231.5}-\mathrm{BT}_{1097.25}=-1.05 \mathrm{~K}$. Next $\mathrm{SO}_{2}$ clouds were introduced between 17 and $19 \mathrm{~km}$ with total column densities of 10 and 100 DU. In the left panel of Fig. 3, the difference between spectra with background $\mathrm{SO}_{2}$ and the spectra with 10 and $100 \mathrm{DU}$ is shown. An $\mathrm{SO}_{2}$ column of 10 (100) DU gives $\mathrm{BTD}_{\mathrm{I}}=-0.99(-0.47) \mathrm{K}$ implying that the 1231.5 and $1097.25 \mathrm{~cm}^{-1}$ channel differences do not become positive for realistic $\mathrm{SO}_{2}$ amounts.

If ice clouds are present somewhere in the same atmospheric column as the ash cloud, they may also have an impact on BTD . Further radiative transfer simulations were made to assess this effect. In the right panel of Fig. 3 the simulated $1231.5-1097.25 \mathrm{~cm}^{-1}$ brightness temperature difference as a function of ice water content and ice cloud top height is shown. The water ice cloud was $1 \mathrm{~km}$ thick. From Fig. 3 it is clear that BTD I becomes larger than $1.5 \mathrm{~K}$ for ice clouds at altitudes greater than about $15 \mathrm{~km}$ and ice water contents around $0.1 \mathrm{~g} \mathrm{~cm}^{-3}$. For the episode under investigation here, CALIOP (Cloud-Aerosol Lidar with Orthogonal Polarization) data shows that cirrus cloud were present below $15 \mathrm{~km}$ (see Fig. 2e Kristiansen et al., 2015). Hence to mini- mize the effect of absorption by $\mathrm{SO}_{2}$ and the effect of ice clouds on ash detection it is required that $\mathrm{BTD}_{\mathrm{I}}>1.5 \mathrm{~K}$. It is noted that the choice of $1.5 \mathrm{~K}$ is conservative and that a lower value will identify more pixels as ash, but at the expense of more false positives, especially if ice clouds are present.

In the right panels of Figs. 1 and 2, BTD I is shown including a contour line at $1.5 \mathrm{~K}$. For 14 February 2014, 02:53 UTC the area identified as ash by IASI overlaps with the area detected by AVHRR/3 (left panel) but is somewhat larger. For 15 February 2014, 02:29-02:35 UTC, Fig. 2, IASI detects ash whereas AVHRR/3 does not. To further understand why ash is identified by IASI and not AVHRR/3, IASI spectra between 700 and $1225 \mathrm{~cm}^{-1}$ shown in Fig. 4 with locations marked by black stars in the right panels of Figs. 1 and 2, and listed in Table 1, are investigated in detail using radiative transfer modelling.

\section{Radiative transfer modelling}

Modelled high resolution infrared spectra may be used to retrieve aerosol and ice cloud properties from measured spectra. For example Newman et al. (2012) estimated aerosol 

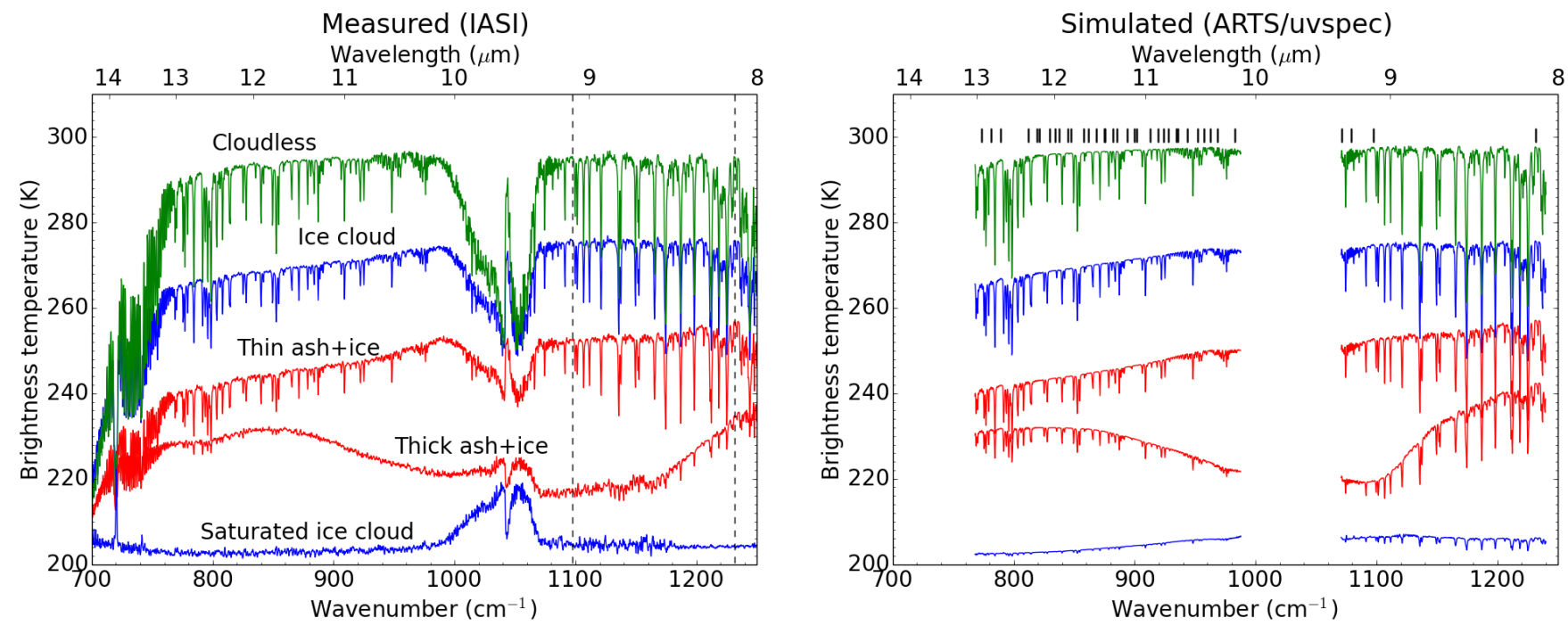

Figure 4. (Left panel) Measured IASI/MetOp-A spectra for the pixels marked in the right panels of Figs. 1 and 2, and listed in Table 1. The dashed vertical lines are at 1231.5 and $1097.25 \mathrm{~cm}^{-1}$, the channels used to calculate BTD . (Right panel) IASI spectra simulated by ARTS/uvspec. The regions affected by ozone, between about 988 and $1070 \mathrm{~cm}^{-1}$, and carbon dioxide absorption, below about $768 \mathrm{~cm}^{-1}$, have been omitted for clarity. The black vertical lines indicate the wavelengths used in the estimation of ash and ice contents. See Sect. 4.2 for further details.

mass loading for the Eyjafjallajökull 2010 eruption using IASI measurements and the radiative transfer model described by Clarisse et al. (2010a); Ishimoto et al. (2016) estimated the refractive index of ash from several volcanic eruptions using simulated spectra and data from the Atmospheric Infrared Sounder (AIRS); and Wang et al. (2013) used a highspectral-resolution cloud-sky radiative transfer model to retrieve ice cloud properties from 14 AIRS narrow spectral bands. Here IASI spectra with varying amounts of ash, ice, ash and ice were modelled. First line-by-line gaseous absorption optical depths were calculated by the Atmospheric Radiative Transfer Simulator (ARTS) model (Eriksson et al., 2011). Next, the gaseous absorption optical depths were used as input to the uvspec radiative transfer model (Mayer and Kylling, 2005; Emde et al., 2016). In addition to gaseous absorption, water ice clouds and volcanic ash clouds were added as described below.

\subsection{Individual spectra}

Vertical profiles of temperature, pressure, $\mathrm{H}_{2} \mathrm{O}, \mathrm{O}_{3}, \mathrm{CH}_{4}$, $\mathrm{N}_{2} \mathrm{O}$, and $\mathrm{CO}_{2}$ and the surface temperature were obtained from non-cloudy retrievals in the L2 product from IASI (Schlüssel et al., 2005) for the scene from 15 February 2014. Atmospheric profiles for temperature, pressure and each trace gas, were made by averaging all the non-cloudy profiles.

The parts of the scenes containing ash are mostly over water; hence the surface emissivity was set equal to sea water (MODIS - University of California, Santa Barbara (UCSB)
Emissivity Library; the measurement procedure is described in Snyder et al. (1997). No topography was included.

CALIOP data indicate that the ash plume over the vent reached altitudes between 17 and $26 \mathrm{~km}$. Other clouds were present between 10 and 15 km, (see Fig. 2e Kristiansen et al., 2015). The IASI scenes investigated here were recorded 1 and 2 days after the CALIOP overpass. We assume that the transported ash cloud is between altitudes of 17 and $18 \mathrm{~km}$. This assumption is supported by dispersion model simulations, (see Figs. 2c and 3b Kristiansen et al., 2015). For the ash the refractive index of andesite from Pollack et al. (1973) was used as the major rock types of Kelud are andesite/basaltic andesite and basalt/picro-basalt according to the Global Volcanism Program of the Smithsonian Institution (http://volcano.si.edu). The ash particles were assumed to be spherical and to have a lognormal size distribution with geometric standard deviation of 2.0. The ash cloud was assumed to be vertically homogeneous and the ash mass loading and the ash particle radius were varied.

For the simulations with an ice cloud, the ice cloud was assumed to be $1 \mathrm{~km}$ thick and vertically homogeneous. The ice particles were assumed to consist of solid columns with $r_{\text {eff }}=40.0 \mu \mathrm{m}$. In the latest libRadtran version (Emde et al., 2016), the shortwave parameterization by Key et al. (2002) has been extended to the thermal region to wavenumbers of $100 \mathrm{~cm}^{-1}$. As such, the optical properties of the ice clouds are based on single scattering calculations for the solid columns and measured size distributions. The ice cloud altitude and the ice water content were varied. 


\subsection{Ash and water ice cloud properties}

Measured spectra were compared with simulated spectra to get an estimate of the ash mass loading, ash particle radius, ice water content and ash cloud altitude. However, the measured IASI spectra contain numerous trace gas absorption lines. The ash and ice optical properties vary comparatively slowly with wavelength; hence only wavelengths for which trace gases have minimal influence were selected to estimate the ash and ice cloud properties. Characterization of atmospheric constituents by using selected IASI channels have been done by others. For example Peyridieu et al. (2013) devised a three-step algorithm for dust aerosols characterization. In the first step they used six IASI channels to determine the atmospheric state; the next eight IASI channels were used to determine the aerosol optical depth and mean layer altitude, and retrieved the coarse mode effective radius in the third step. In the present study a total of 77 IASI channels were initially selected from the brightest channel per interval of $5 \mathrm{~cm}^{-1}$ in the ranges $770-985$ and $1070-1240 \mathrm{~cm}^{-1}$ following Clarisse et al. (2010b). Visual comparisons of measured and simulated spectra and excluding the region between 1097.25 and $1231.25 \mathrm{~cm}^{-1}$ possibly affected by $\mathrm{SO}_{2}$, further decreased the number of channels to 37 . The location of these channels is shown in the right panel of Fig. 4 as black vertical lines.

Spectra were simulated for three cases.

- Ice cloud only - The ice cloud top height was taken to be $8,8.5,9,9.5,10,10.5,11,11.5,12,12.5,13 ., 13.5$, $14,14.5,15,16,17$, and $18 \mathrm{~km}$. For each altitude the ice water content was $0.001,0.002,0.005,0.01,0.0125$, $0.015,0.02,0.03,0.04,0.05,0.075,0.1,0.2,0.3,0.4$, $0.5,1.0 \mathrm{~g} \mathrm{~m}^{-3}$.

- Ash cloud only - The ash cloud top was at $18 \mathrm{~km}$. Ash mass concentrations of $0.0001,0.00025,0.0005$, $0.00075,0.001,0.0015,0.002,0.0025,0.003,0.0035$, $0.004,0.005,0.006,0.007,0.008,0.009,0.010,0.02$, $0.03,0.05,0.75,0.1,0.5$ and $1.0 \mathrm{~g} \mathrm{~m}^{-3}$ and ash cloud effective particle radii of $1,2,3 \ldots 9$, and $10 \mu \mathrm{m}$ were considered.

- Ash cloud and ice cloud - This case included an ash cloud with top at $18 \mathrm{~km}$ and ice clouds as specified for the ice cloud only case. The ice water content was varied, as in the ice cloud only case. For each ice cloud the ash mass loading and effective radius were varied, similar to the ash cloud only case.

A total of 306 "ice cloud only", 96 "ash cloud only", and 29376 "ash cloud and ice cloud" spectra were calculated.

For a measured spectrum the brightness temperature was extracted for the $n=37$ channels above, and the root mean square difference (RMSD) was calculated

$\operatorname{RMSD}=\sqrt{\frac{\sum_{i=1}^{n}\left(y_{i}^{\mathrm{m}}-y_{i}^{\mathrm{s}}\right)^{2}}{n}}$,

where $y^{\mathrm{m}}$ and $y^{\mathrm{s}}$ are the measured and the simulated spectra, respectively. The ash and ice cloud used for the simulated spectrum with the smallest RMSD was said to represent the atmospheric state reflected in the measured spectrum. The "ash cloud only" and "ash cloud and ice cloud" cases were included in the estimate only for pixels identified as ash. The RMSD in Eq. (1) gives equal weight to all data points, and hence unequal weight to the to wavenumber regions, 7501000 and $1070-1250 \mathrm{~cm}^{-1}$. Using a weighted RMSD where equal weight was assigned to the two wavenumber regions generally gives slightly larger RMSD.

\section{Results}

Both analysis of individual spectra and complete scenes were made to better understand the effect of ice and ash clouds on the measured spectra. But first examples of the effects of ash and water ice clouds on IASI brightness temperatures are demonstrated.

\subsection{Ash and ice cloud radiative effects}

In the left panel of Fig. 5 the brightness temperature at $773.5 \mathrm{~cm}^{-1}$ as a function of ice water content for ice clouds at various altitudes is shown. The brightness temperature decreases with increasing ice water content and increasing ice cloud altitude. The cloud becomes opaque for an ice water content larger than about $0.3 \mathrm{~g} \mathrm{~m}^{-3}$ for all ice cloud altitudes and the brightness temperatures then reflects the ambient temperature.

In the right panel of Fig. 5 the brightness temperatures for various ash clouds and ash and ice clouds in combination are shown. The brightness temperature for an effective ash particle radius $r_{\mathrm{e}}=1.0 \mu \mathrm{m}$ (red line), decrease with increasing ash mass loading and saturates for an ash mass loading of about $100 \mathrm{~g} \mathrm{~m}^{-2}$. For a larger particle radius, $r_{\mathrm{e}}=4.0 \mu \mathrm{m}$ (yellow line), the brightness temperature saturates at a slightly smaller mass loading. Including an ice cloud at $13 \mathrm{~km}$ below the ash cloud at $18 \mathrm{~km}$ (blue and green lines) shift the curves towards lower brightness temperatures for ash mass loadings smaller than the saturation value for the ash-only case. The leftward shift is larger for denser ice clouds, as is seen when comparing the blue and green lines.

The behaviour of the brightness temperature will generally be similar for other wavelengths, albeit different in magnitude due to the wavelength dependence of the ice water and ash cloud optical properties. This wavelength dependence is used below to obtain the combination of ash and ice water clouds that best fit the measured spectra. 

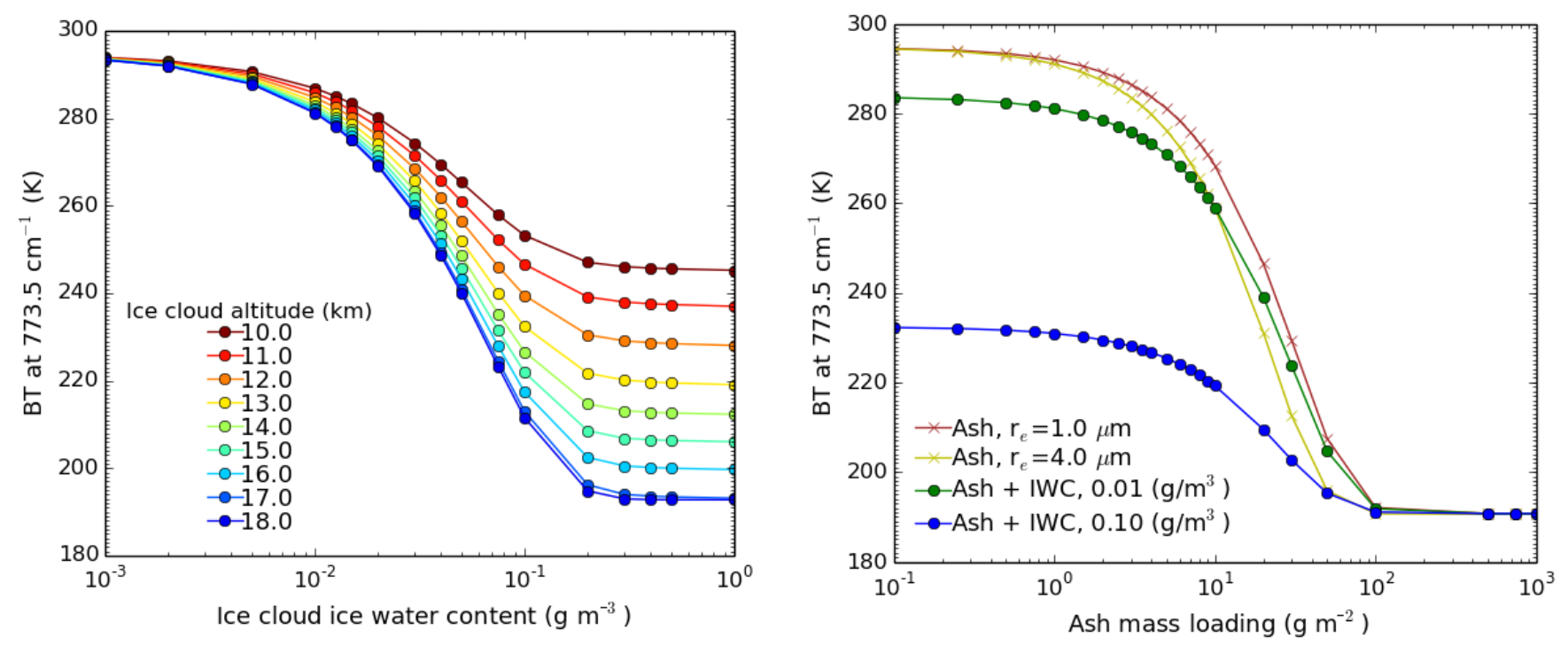

Figure 5. (Left panel) The brightness temperature at $773.5 \mathrm{~cm}^{-1}$ as a function of ice water content for ice clouds at various altitudes. (Right panel) The $773.5 \mathrm{~cm}^{-1}$ brightness temperature as a function of ash mass loading for pure ash cloud (lines with crosses) with effective radii $r_{\mathrm{e}}=1.0,4.0 \mu \mathrm{m}$, and an ash cloud with $r_{\mathrm{e}}=1.0 \mu \mathrm{m}$ overlying an ice cloud at $13 \mathrm{~km}$ with IWC $=0.01$ and $0.1 \mathrm{~g} \mathrm{~m}^{-3}$ (lines with circles).

\subsection{Individual spectra}

The measured IASI spectra for the star marked locations in the right panels of Figs. 1 and 2 are shown in left panel of Fig. 4. The spectrum identified as saturated ice cloud (lower blue curve) appears saturated for nearly all wavenumbers except for the ozone band centred around $1050 \mathrm{~cm}^{-1}$. The higher brightness temperatures in the ozone band implies that this radiation was emitted at a higher altitude in the stratosphere where the temperature is higher than at the altitude of the ice cloud. The rather low and fairly constant overall temperature indicates that this is an ice cloud and that it is opaque. In contrast, the spectra labelled cloudless (green curve in Fig. 4) have brightness temperatures representative for the ocean at these latitudes. A number of trace gas absorption lines are also readily seen. In the cloudless spectrum the ozone band has a lower brightness temperature then at lower and higher wavenumbers, indicating that the radiation in the ozone band was emitted at a higher and colder altitudes than the surface. The red curves in the left panel of Fig. 4 are identified as ash by the IASI BTD I method (see also Table 1). These spectra have a lower brightness temperature than the cloudless spectrum indicating a lower effective emitting temperature. Between 800 and $1000 \mathrm{~cm}^{-1}$ the overall behaviour of the ash spectra is both an increase (thin ash+ice) and decrease (thick ash+ice) with increasing wavenumber. Above about $1200 \mathrm{~cm}^{-1}$ the brightness temperature of the cloudless spectrum generally decrease with increasing wavenumber. For the ash spectra the brightness temperature increase with increasing wavenumber for the channels not affected by gaseous absorption. The ice cloud spectrum is spectrally flat except for the ozone band. This behaviour is reflected in
$\mathrm{BTD}_{\mathrm{I}}$ and $\mathrm{BTD}_{\mathrm{A}}$ in Table 1, and explains why IASI identifies ash on 14 and 15 February, while in the AVHRR/3 data ash is only identified on 14 February. This is similar to the behaviour of the spectra from the Eyjafjallajökull eruption discussed by Clarisse et al. (2010b) in their Fig. 2. They present two spectra; one gives negative $\mathrm{BTD}_{\mathrm{A}}$, the other not, while both give $\mathrm{BTD}_{\mathrm{I}}>0.5$. They conclude that the spectrum with positive $\mathrm{BTD}_{\mathrm{I}}$ contains both volcanic ash and ice. A second not saturated ice cloud example is also shown in Fig. 4 and labelled "ice cloud". Between 800 and $1000 \mathrm{~cm}^{-1}$ it behaves similarly to the thin ash+ice cloud example, compare $\mathrm{BTD}_{\mathrm{A}}$ in Table 1 , while the $\mathrm{BTD}_{\mathrm{I}}$ is small, $0.1 \mathrm{~K}$, to be compared with $4.11 \mathrm{~K}$ for the thin ash+ice example.

For the measured spectra in the left panel of Fig. 4, the corresponding ARTS/uvspec simulated spectra are shown in the right panel of Fig. 4. In the simulated spectra the $\mathrm{O}_{3}$ and $\mathrm{CO}_{2}$ absorption features centred at about $1050 \mathrm{~cm}^{-1}$ and below $768 \mathrm{~cm}^{-1}$, respectively, have been left out to better visualize the broad band effects of ash and ice clouds. The ash mass loading, effective radius, ice water content and ice cloud top height used to simulate the various spectra, are listed in Table 1 . These values were those that gave the smallest RMSD compared with the measured spectra, see Sect. 4.2.

The saturated ice cloud spectrum is best modelled by an atmosphere including an ice cloud with top at $16 \mathrm{~km}$ and ice water content of $0.2 \mathrm{~g} \mathrm{~m}^{-3}$, while an ice water content of $0.03 \mathrm{~g} \mathrm{~m}^{-3}$ was used for the ice cloud example. The simulated cloudless spectrum also include an ice cloud at $16 \mathrm{~km}$ with a very low ice water content which has only a small effect on the brightness temperature, see also left panel of Fig. 5. For the ash-affected spectra the simulated spectra that gave the smallest RMSD for the ice-only, ash-only, and ash 


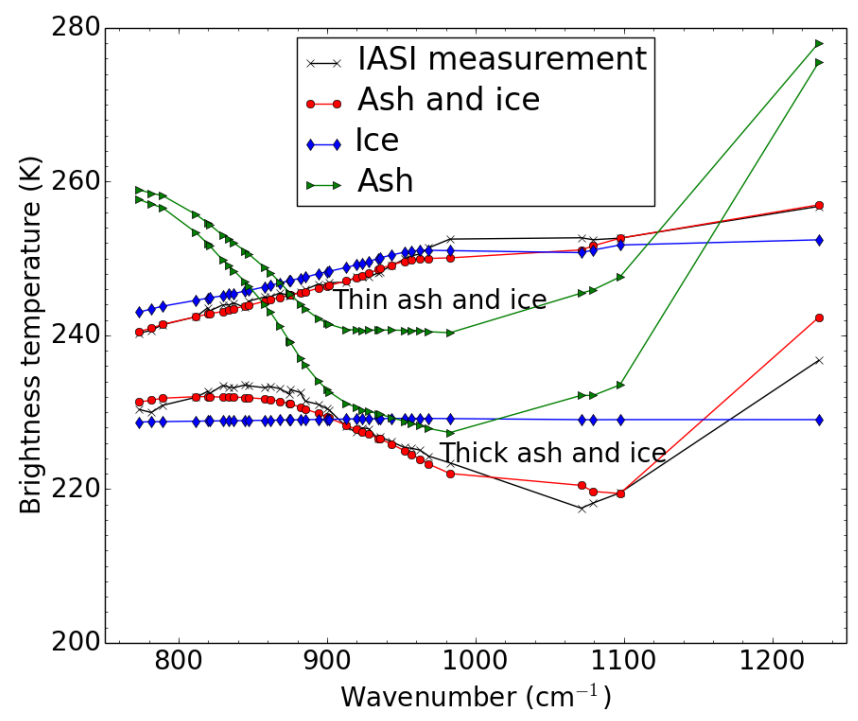

Figure 6. The brightness temperature for the pixels identified as ash in the right panels of Figs. 1 and 2, and marked as thick and thin ash and ice examples in the left panel of Fig. 4 and in Table 1. The brightness temperature is shown only for points which are used to calculate the RMSD, Eq. (1). The various colours refers to the three cases described in Sect. 4.2. Note that the lines connecting the points are drawn just for visualisation and do not represent the actual spectral behaviour between the data points.

and ice cases, are shown in Fig. 6. Only the data points used to calculate the RMSD in Eq. (1) are shown. The ash-only case (green lines, Fig. 6) clearly does not reproduce the measured spectral behaviour (black lines, Fig. 6). The ice-only case (blue lines, Fig. 6), does not reproduce the measured spectrum for the thick ash and ice example spectrum, but comes close for the thin ash+ice example. However, for all the example spectra the ash and ice case (red lines, Fig. 6) best reproduce the measured spectra. Thus, the spectra said to include ash in the left panel of Fig. 4, are all best simulated by including both ash and ice clouds.

The large footprint of IASI is covered by several AVHRR $/ 3$ pixels. For the spectra in Fig. 4 the brightness temperatures in bands $4\left(\mathrm{BT}_{4}\right)$ and $5\left(\mathrm{BT}_{5}\right)$ of AVHRR/3 are shown vs. each other in the right panel of Fig. 7. In the left panel of Fig. 7 is shown $\mathrm{BT}_{4}$ vs. $\mathrm{BT}_{4}-\mathrm{BT}_{5}$. There is little variation in $\mathrm{BT}_{4}$ for the cloudless and saturated ice cloud examples as seen in Fig. 7 and in the sixth column of Table 1 which gives the standard deviation of $\mathrm{BT}_{4}$ as $0.1 \mathrm{~K}$ for the cloudless and $1.1 \mathrm{~K}$ for the saturated ice cloud examples. For the examples identified as containing ash and ice, the standard deviation is larger. Thus, the part of the atmosphere and underlying surface viewed by these IASI pixels are inhomogeneous and the IASI spectra represent the contributions from all these various atmospheric states. Thus, while discussing which modelled spectrum that best represents the measured spectrum, it must be kept in mind that the mea- sured spectrum represents an inhomogeneous atmosphere and the modelled derived values may thus not necessarily represent the actual atmospheric state. Inhomogeneities in IASI footprints also affect other applications, for example current methods cannot correctly retrieve cloud pressures for multi-layer systems, which represents at least half of the cloudy situations recorded by IASI (Lavanant et al., 2011). Below the ash and ice clouds that best reproduced the IASI scenes in the right panels of Figs. 1 and 2 are presented.

The frequencies of the ash mass loading and RMSD are shown in Fig. 10.

\subsection{Ash and ice clouds}

The method presented in Sect. 4.2 was used to estimate the ice and ash cloud properties that best reproduced the IASI spectra for the scenes shown in Figs. 1 and 2. The ice water content, ice cloud height, and volcanic ash mass load are shown together with the RMSD in Figs. 8 and 9 for 14 and 15 February, respectively. The frequencies of the ash mass loading and RMSD are shown in Fig. 10. The mean ash mass load decrease from 2.1 to $1.1 \mathrm{~g} \mathrm{~m}^{-2}$ between the 14 and 15 February overpasses, upper right panels Figs. 8 and 9 and panels in upper row, columns 1 and 2 of Fig. 10. For both overpasses the maximum ash load is $9.0 \mathrm{~g} \mathrm{~m}^{-2}$. When not including ash and ice spectra in the analysis, the maximum and mean values increase to 50.0 and $26.4 \mathrm{~g} \mathrm{~m}^{-2}, 14$ February, and 50 and $12.4 \mathrm{~g} \mathrm{~m}^{-2}, 15$ February, panels in lower row, columns 1 and 2 of Fig. 10. Hence, more ash is retrieved when ice clouds are not included. Kristiansen et al. (2015) reported maximum and mean ash loads of 26.63 and $0.22 \mathrm{~g} \mathrm{~m}^{-2}$ for 14 February, 02:32 UTC. These values are not directly comparable to those presented here as they retrieved values for the full cloud while only part of the cloud is visible in the Fig. 1. Nevertheless the present values and the values of Kristiansen et al. (2015) are within the same range considering the uncertainties (Corradini et al., 2008).

For 14 February there is considerable ice in the same column as the volcanic ash, upper left panel Fig. 8, and for some pixels it is identified as being at the same altitude as the ash cloud, lower left panel Fig. 8. For 15 February there is generally less ice in the ash-affected pixels, upper left panel Fig. 9. For the largest area identified as ash, the ice cloud is at the same altitude as the ash cloud, lower left panel Fig. 9.

For both scenes the RMSD for pixels identified as ash is generally smaller than pixels not identified as ash, see lower right panels Figs. 8 and 9 and panels in upper row, columns 3 and 4 of Fig. 10. The frequency of the RMSD is similar for pixels identified as ash and those not identified as ash, compare green and red bars in panels in columns 3 and 4, upper row, of Fig. 10, and also compare mean and standard deviation between rows 1 and 2 and rows 5 and 6 in Table 2 . Hence, when including modelled ash and ice, ash-only and ice-only spectra in the measurement-model comparison, the 

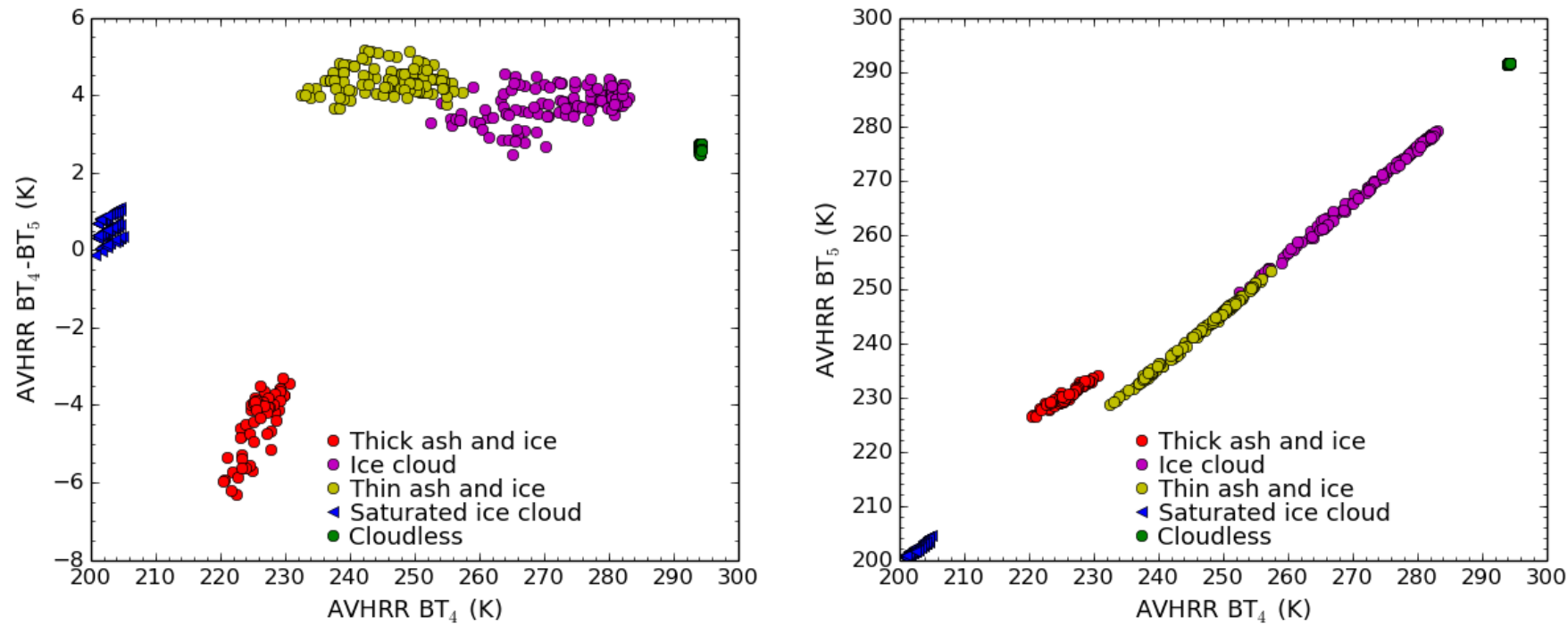

Figure 7. (Left panel) Measured AVHRR/3 $\mathrm{BT}_{4}$ vs. $\mathrm{BT}_{4}-\mathrm{BT}_{5}$ for the pixels marked in the right panels of Figs. 1 and 2 and listed in Table 1. (Right panel) Measured AVHRR/3 $\mathrm{BT}_{4}$ vs. $\mathrm{BT}_{5}$ for the same pixels as in left panel.
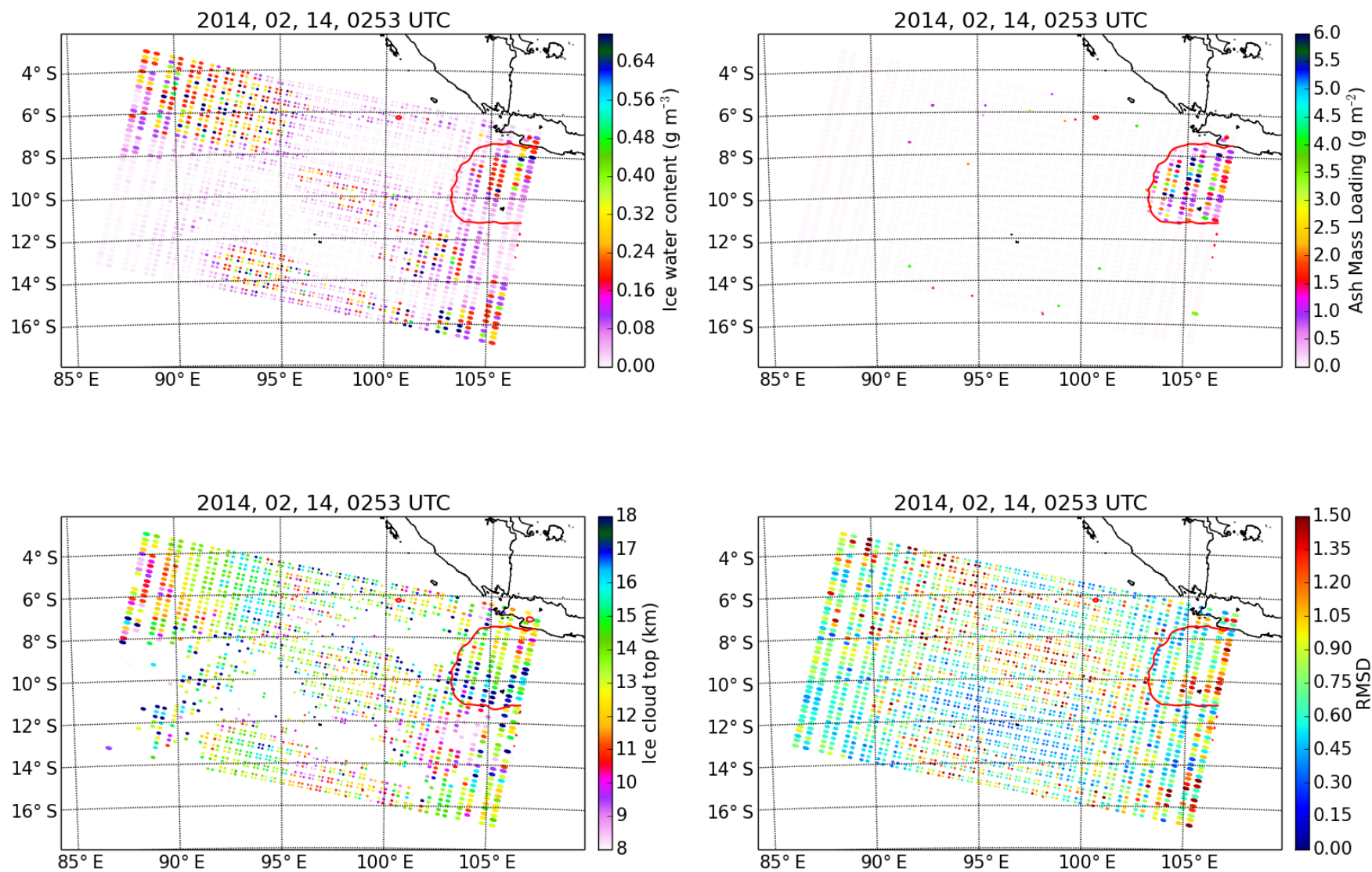

Figure 8. (Upper left panel) The estimated ice water content. (Upper right panel) The estimated ash mass loading. (Lower left panel) The estimated altitude of the ice cloud top height for ice clouds with ice water content $>0.01 \mathrm{~g} \mathrm{~m}^{-2}$. (Lower right panel) The root mean square difference (RMSD) of the simulated-measured spectra. The red contour line delineates the area identified as ash. Data from 14 February 2014, 02:53 UTC. 

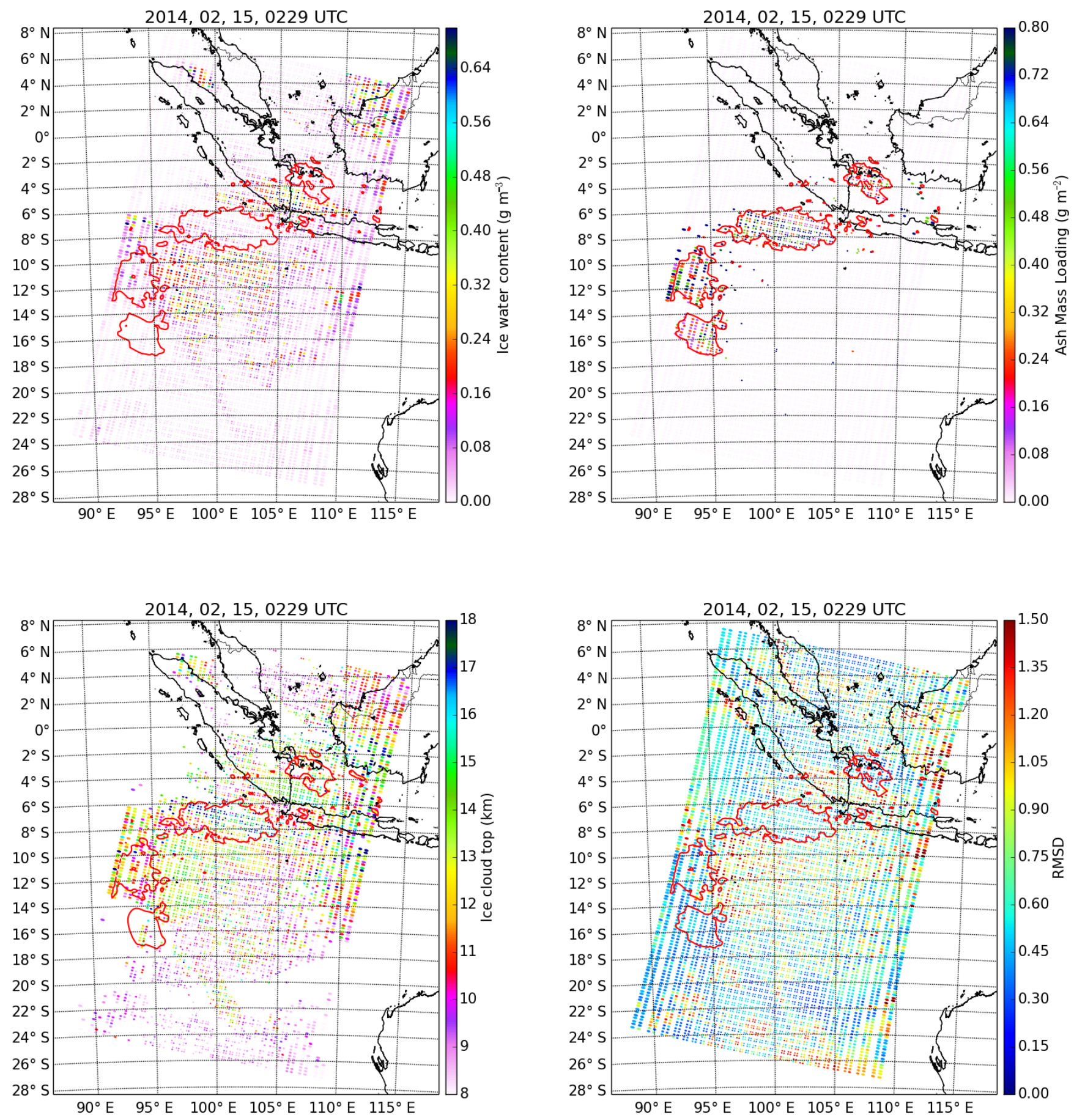

Figure 9. (Upper left panel) The estimated ice water content. (Upper right panel) The estimated ash mass loading. (Lower left panel) The estimated altitude of the ice cloud top. height for ice clouds with ice water content $>0.01 \mathrm{~g} \mathrm{~m}^{-2}$. (Lower right panel) The root mean square difference (RMSD) of the simulated-measured spectra. The red contour line delineates the area identified as ash. Data from 15 February 2014, 02:29-02:35 UTC. 

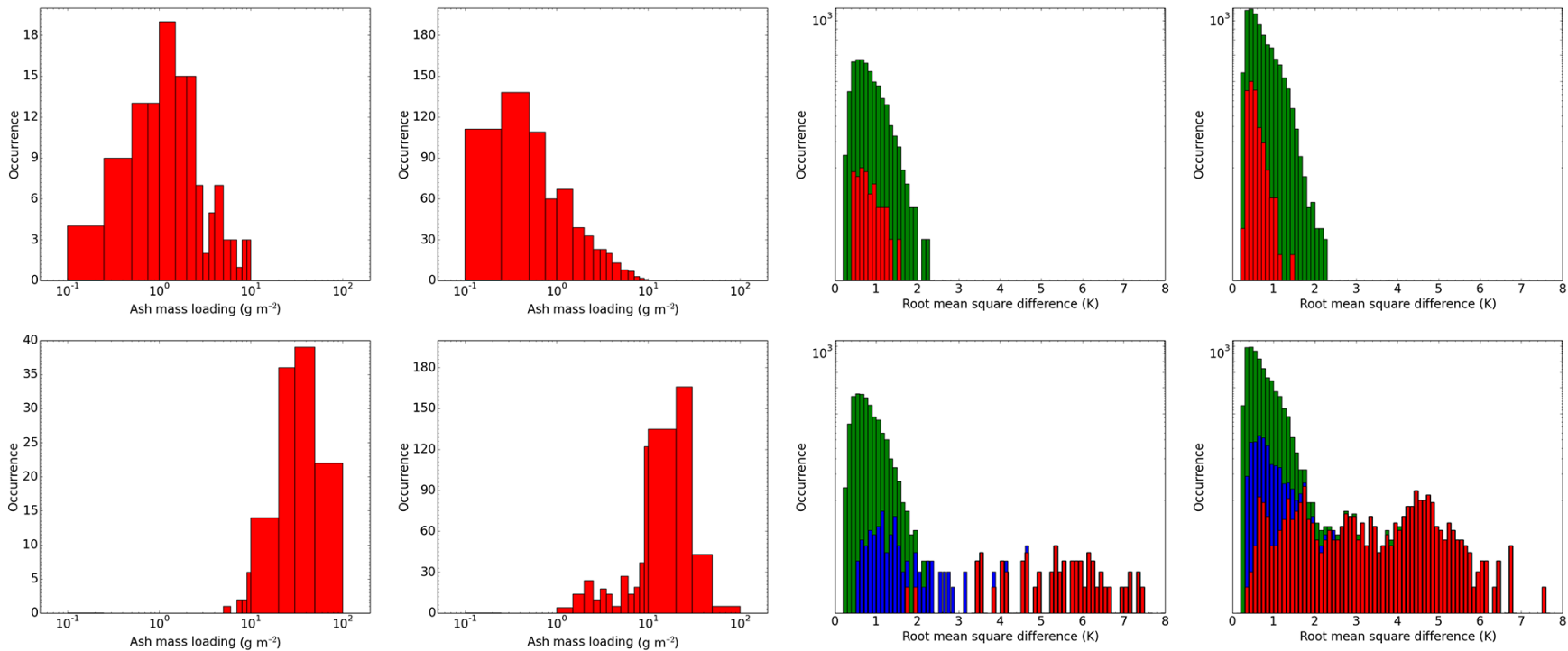

Figure 10. (Upper row) The frequency of the ash mass loading (columns 1 and 2) and the RMSD (columns 3 and 4) when including all types of simulated spectra. (Lower row) The frequency of the ash mass loading (columns 1 and 2) and the RMSD (columns 3 and 4 ) when not including spectra with both ash and ice. In columns 3 and 4, the red bars represents ash-affected pixels while the green bars are all other pixels. The blue bars represents the ash-affected pixels but modelled ice spectra were used to calculate the RMSD, see text for details. Note $\log$-scale on $y$ axis for panels in columns 3 and 4. Columns 1 and 3: data from 14 February 2014. Columns 2 and 4: data from 15 February 2014.

ash-affected spectra are reproduced to a similar accuracy to those not affected by ash.

If the modelled spectra including both ash and ice are excluded from the comparison and the ash-only and ice-only included, the ash mass loading shifts to larger values as shown in the lower row of Fig. 10, panels in columns 1 and 2. Also the RMSD gets markedly worse, compare red bars in the bottom row, columns 3 and 4 panels of Figs. 10 with the red bars in the upper row, and the mean and standard deviations of rows 2 and 4 and rows 6 and 8 in Table 2. Hence, modelled spectra including both ash and ice clouds reproduce the measured ash-affected spectra better than using modelled spectra with ash only.

If all ash-identified pixels are to be reproduced with iceonly spectra, the RMSD gets closer to the RMSD for the spectra including both ash and ice, compare red bars in the upper row, column 3 and 4 panels of Fig. 10 with blue bars in bottom row, and the mean and standard deviations of rows 2 and 3 and rows 6 and 7 in Table 2. While the mean and standard deviations in Table 2 are not too different, the improvement of using ash and ice spectra vs. ice-only spectra becomes clear when comparing the RMSD for each pixel for the two approaches as shown in Fig. 11. If the two approaches had been of similar merit the data points would be symmetric around the $1: 1$ line. However, the RMSD is generally larger for the ice-only case; hence generally the modelled spectra with both ash and ice reproduce the measured spectra better.

\section{Discussion}

Above it was shown that modelled spectra including both ash and ice clouds better reproduced the IASI measured spectra compared to modelled spectra including only ash. While considerable detail was included in the simulated spectra some of the limitations of the study are discussed here.

Water clouds and mixed phase clouds are not considered in this study. Hu et al. (2010) used combined CALIOP, Imaging Infrared Radiometer (IIR) and MODIS measurements to show that supercooled water clouds may be present for temperatures down to about $-35^{\circ} \mathrm{C}$. For the case studied here the temperature is below $-35^{\circ} \mathrm{C}$ for altitudes larger than about $10 \mathrm{~km}$. Here, all ice clouds are assumed to be $8 \mathrm{~km}$ or higher in altitude, but very few of the estimated ice cloud altitudes are below $10 \mathrm{~km}$. It is noted that $\mathrm{Hu}$ et al. (2010) found very few supercooled clouds for latitudes between $40^{\circ} \mathrm{S}$ and $40^{\circ} \mathrm{N}$ which includes the area investigated here. On the other side the CALIOP data presented in Fig. 2e of Kristiansen et al. (2015) indicate some clouds around $5 \mathrm{~km}$. However, to keep the computational burden manageable, low altitude liquid water clouds were not included in the analysis.

The ice cloud particles were assumed to be solid columns with a mean effective radius of $40 \mu \mathrm{m}$. According to Faijan et al. (2012), the shapes and sizes of ice particles change with location within the cloud, with small droxtals in the top, pristine hexagonal columns in the middle, and larger irregular aggregates in the bottom layer. The uncertainty in crystal shape can lead to uncertainty in the brightness temperature of sev- 
Table 2. The mean and standard deviation of the frequency distributions shown in Fig. 10.

\begin{tabular}{llcc}
\hline Row & Description & Mean & Standard deviation \\
\hline & & 14 Feb 2014 & \\
\hline 1 & All pixels (green bars, upper row, panel in column 3 of Fig. 10) & 0.79 & 0.33 \\
2 & Ash-only pixels (red bars, upper row, panel in column 3 of Fig. 10) & 0.79 & 0.28 \\
3 & Ash-only pixels assumed to be ice (blue bars, lower row, panel in column 3 of Fig. 10) & 1.46 & 0.77 \\
4 & Ash-only pixels assumed to be ash-only (red bars, lower row, panel in column 3 of Fig. 10) & 5.12 & 1.60 \\
\hline & & & 0.67 \\
\hline 5 & All pixels (green bars, upper row, panel in column 4 of Fig. 10) & 0.52 & 0.32 \\
6 & Ash-only pixels (red bars, upper row, panel in column 4 of Fig. 10) & 0.78 & 0.32 \\
7 & Ash-only pixels assumed to be ice (blue bars, lower row, panel in column 4 of Fig. 10) & 3.21 & 1.67 \\
\hline
\end{tabular}
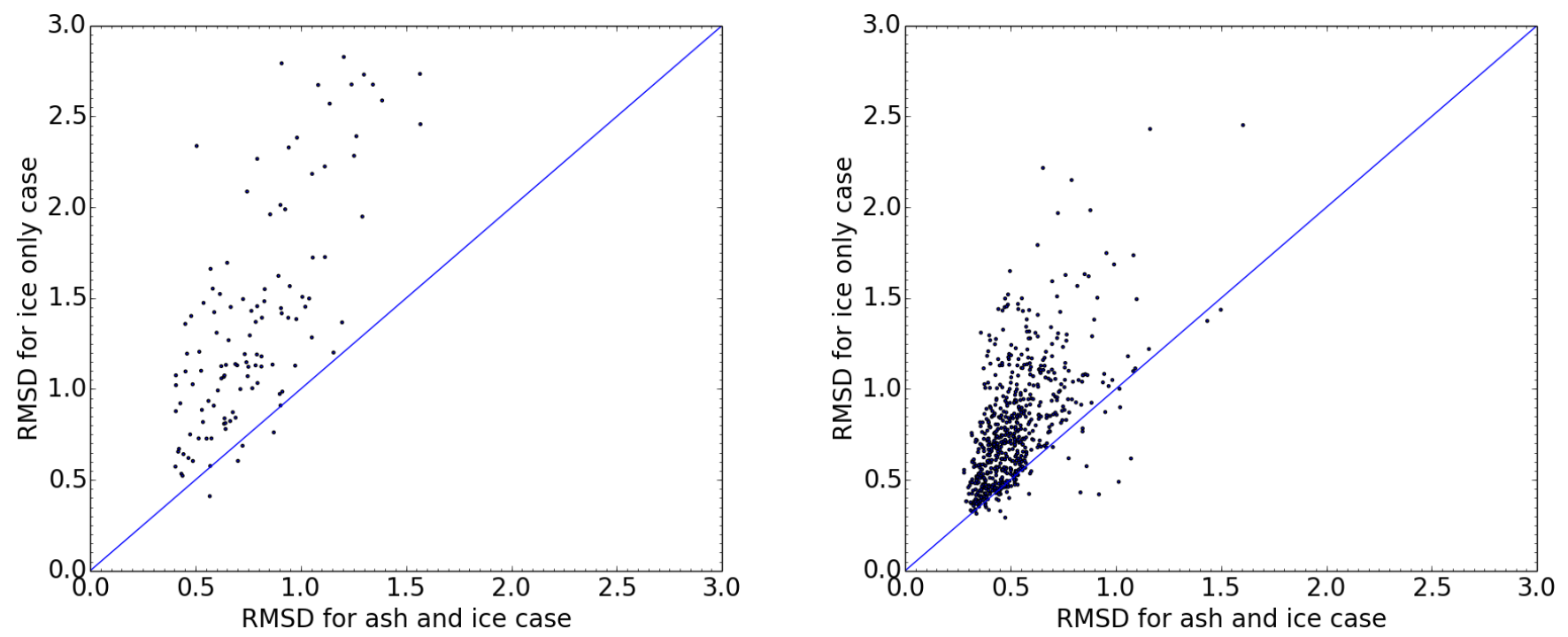

Figure 11. The RMSD for the ash and ice case vs. the ice-only case for 14 February 2014 (left panel) and 15 February 2014 (right panel).

eral Kelvin. Similar conclusions were made by Dubuisson et al. (2008) who investigated the effect of ice cloud microphysics on top of the atmosphere thermal radiation. Hyperspectral infrared sounders may be used to detect cloud microphysical properties. For example Li et al. (2005) retrieved cloud microphysical properties from MODIS and the Atmospheric Infrared Sounder (AIRS). However, no such attempt was made here. But it is noted that other ice cloud particle assumptions might yield different results.

$\mathrm{SO}_{2}$ was also released during the eruption. While outside the scope of the present work, it would be of great interest to investigate how the presence of ash and/or ice clouds affects the $\mathrm{SO}_{2}$ signature in the IASI spectra.

The ash was assumed to be andesite. A different composition will have a different refractive index which will change the spectral shape of the simulated spectra and hence may yield other ash and ice cloud estimates than those presented. Ishimoto et al. (2016) estimated the refractive index of vol- canic ash from numerous eruptions using AIRS data. For the Kelud 2014 eruption a refractive index based on the combination of the basalt and rhyolite refractive indices of Pollack et al. (1973) was derived. Ishimoto et al. (2016) can not rule out the effect of ice water cloud contamination and propose that the petrological properties of the Kelud 2014 eruption should be investigated.

The shape of ash particles were assumed to be spherical. It has been shown by Kylling et al. (2014) that the assumption of spherical particles may underestimate the retrieved ash mass loading by tens of percent compared to porous nonspherical particles. Also, no internal mixing of ash and ice was included. However, external mixing of ash and ice was included when both clouds were at $18 \mathrm{~km}$.

For all calculations the ash cloud was assumed to be at 18 and $1 \mathrm{~km}$ thick. Moving the ash cloud up and down a few kilometres and changing its thickness will affect the results as demonstrated by Corradini et al. (2008). However, due to 
the computational burden, other ash clouds geometries were not considered.

Scatter plot (not shown) of the ash mass loading vs. the ice water content for the ash-affected pixels show no correlation between the two. Thus, the ash and ice clouds appear to be independent of each other. However, for a number of pixels the colocation of the ice and ash at the same altitude gave the best agreement with the IASI measurements. Ice was most likely present in the volcanic cloud, in addition meteorological water ice clouds were present at other levels. The latter is supported by CALIOP data, Fig. 2e of Kristiansen et al. (2015), which show that ice water clouds are present between 10 and $15 \mathrm{~km}$. This supports the present analysis where ice clouds are found at both the same altitude as the ash cloud implying ice in the volcanic cloud, and at lower altitudes indicating the presence of meteorological water ice clouds.

\section{Conclusions}

Two scenes during the Mt Kelud February 2014 eruption have been studied using the hyperspectral IASI and broad band AVHRR/3 instruments onboard the MetOp-A satellite. The instruments' different capabilities to detect volcanic ash have been discussed and the spectral coverage of IASI explored to investigate the possible presence of both ice and volcanic ash. The main findings of the investigation are the following.

- The spectral coverage and resolution of the IASI instrument gives increased sensitivity to the presence of volcanic ash. As such, the use of IASI data for detection of volcanic ash is a powerful and attractive addition to the use of AVHRR/3 and similar instruments.

- IASI may detect ash when AVHRR/3 and similar instruments such as SEVIRI, MODIS and MTSAT, do not detect ash.

- Comparisons of modelled and measured IASI spectra suggests that during the Mt Kelud 2014 eruption both ash and ice clouds were present simultaneously.

- IASI may potentially retrieve both ash and ice clouds microphysical properties simultaneously.

- Underlying ice clouds reduce the ash needed to reproduce the measured IASI spectra by about a factor of 12 on the average.

Finally, in this study IASI spectra measured during the Mt Kelud 2014 eruption were interpreted in terms of ash and ice clouds. It is noted that this interpretation does not rule out other interpretations based on other ash, ice, and water cloud assumptions not considered here.

\section{Data availability}

IASI and AVHRR data are available from the Comprehensive Large Array-data Stewardship System (CLASS) which is an electronic library of NOAA environmental data (http://www. class.ncdc.noaa.gov/saa/products/welcome, NOAA, 2016). Surface emissivity values are available from the MODIS UCSB Emissivity Library, http://www.icess.ucsb.edu/modis/ EMIS/html/seawater.html (Zhengming Wan’s Group, 2016).

Acknowledgements. Constructive comments from the two anonymous reviewers are highly appreciated. The Centre National d'Etudes Spatiales (CNES, France) developed and built IASI. It is flown onboard the MetOp satellites as part of the EUMETSAT Polar System. NILU receives IASI L1 data from EUMETSAT through the EUMETCAST near real time data distribution service. Part of this study was funded by the Norwegian Ministry of Transport and Communications.

Edited by: A. Kokhanovsky

\section{References}

Clarisse, L., Hurtmans, D., Prata, A. J., Karagulian, F., Clerbaux, C., Maziére, M. D., and Coheur, P.-F.: Retrieving radius, concentration, optical depth, and mass of different types of aerosols from high-resolution infrared nadir spectra, Appl. Opt., 49, 37133722, 2010a.

Clarisse, L., Prata, F., Lacour, J.-L., Hurtmans, D., Clerbaux, C., and Coheur, P.-F.: A correlation method for volcanic ash detection using hyperspectral infrared measurements, Geophys. Res. Lett., 37, L19806, doi:10.1029/2010GL044828, 2010 b.

Clarisse, L., R'Honi, Y., Coheur, P.-F., Hurtmans, D., and Clerbaux, C.: Thermal infrared nadir observations of 24 atmospheric gases, Geophys. Res. Lett., 38, doi:10.1029/2011GL047271, 2011.

Clarisse, L., Coheur, P.-F., Prata, F., Hadji-Lazaro, J., Hurtmans, D., and Clerbaux, C.: A unified approach to infrared aerosol remote sensing and type specification, Atmos. Chem. Phys., 13, 2195 2221, doi:10.5194/acp-13-2195-2013, 2013.

Clerbaux, C., Boynard, A., Clarisse, L., George, M., Hadji-Lazaro, J., Herbin, H., Hurtmans, D., Pommier, M., Razavi, A., Turquety, S., Wespes, C., and Coheur, P.-F.: Monitoring of atmospheric composition using the thermal infrared IASI/MetOp sounder, Atmos. Chem. Phys., 9, 6041-6054, doi:10.5194/acp-9-6041-2009, 2009.

Corradini, S., Spinette, C., Carboni, E., Tirelli, C., Buongiorno, M. F., Pugnaghi, S., and Gangale, G.: Mt. Etna tropospheric ash retrieval and sensitivity analysis using Moderate Resolution Imaging Spectroradiometer Measurements, J. Appl. Remote Sens., 2, 1-20, doi:10.1117/1.3046674, 2008.

DeSouza-Machado, S. G., Strow, L. L., Hannon, S. E., and Motteler, H. E.: Infrared dust spectral signatures from AIRS, Geophys. Res. Lett., 33, L03801, doi:10.1029/2005GL024364, 2006.

Dubuisson, P., Giraud, V., Pelon, J., Cadet, B., and Yang, P.: Sensitivity of thermal infrared radiation at the top of the atmosphere and the surface to ice cloud microphysics, J. Appl. Meteorol. Clim., 47, 2545-2560, 2008. 
Durant, A. J., Shaw, R. A., Rose, W. I., Mi, Y., and Ernst, G. G. J.: Ice nucleation and overseeding of ice in volcanic clouds, J. Geophys. Res., 113, D09206, doi:10.1029/2007JD009064, 2008.

Emde, C., Buras-Schnell, R., Kylling, A., Mayer, B., Gasteiger, J., Hamann, U., Kylling, J., Richter, B., Pause, C., Dowling, T., and Bugliaro, L.: The libRadtran software package for radiative transfer calculations (version 2.0.1), Geosci. Model Dev., 9, 1647-1672, doi:10.5194/gmd-9-1647-2016, 2016.

Eriksson, P., Buehler, S. A., Davis, C. P., Emde, C., and Lemke, O.: ARTS, the atmospheric radiative transfer simulator, version 2, J. Quant. Spectrosc. Ra., 112, 1551-1558, 2011.

Faijan, F., Lavanant, L., and Rabier, F.: Towards the use of cloud microphysical properties to simulate IASI spectra in an operational context, J. Geophys. Res.-Atmos., 117, d22205, doi:10.1029/2012JD017962, 2012.

Gangale, G., Prata, A. J., and Clarisse, L.: The infrared spectral signature of volcanic ash determined from high-spectral resolution satellite measurements, Remote Sens. Environ., 114, 414-425, 2010.

Guo, S., Rose, W. I., Bluth, G. J. S., and Watson, I. M.: Particles in the great Pinatubo volcanic cloud of June 1991: The role of ice, Geochem. Geophy. Geosy., 5, doi:10.1029/2003GC000655, 2004.

Hilton, F., Armante, R., August, T., Barnet, C., Bouchard, A., Camy-Peyret, C., Capelle, V., Clarisse, L., Clerbaux, C., Coheur, P.-F., Collard, A., Crevoisier, C., Dufour, G., Edwards, D., Faijan, F., Fourrié, N., Gambacorta, A., Goldberg, M., Guidard, V., Hurtmans, D., Illingworth, S., Jacquinet-Husson, N., Kerzenmacher, T., Klaes, D., Lavanant, L., Masiello, G., Matricardi, M., McNally, A., Newman, S., Pavelin, E., Payan, S., Péquignot, E., Peyridieu, S., Phulpin, T., Remedios, J., Schlüssel, P., Serio, C., Strow, L., Stubenrauch, C., Taylor, J., Tobin, D., Wolf, W., and Zhou, D.: Hyperspectral Earth Observation from IASI: Five Years of Accomplishments, B. Am. Meteorol. Soc., 93, 347-370, doi:10.1175/BAMS-D-11-00027.1, 2011.

Hu, Y., Rodier, S., Xu, K.-m., Sun, W., Huang, J., Lin, B., Zhai, P., and Josset, D.: Occurrence, liquid water content, and fraction of supercooled water clouds from combined CALIOP/IIR/MODIS measurements, J. Geophys. Res.-Atmos., 115, doi:10.1029/2009JD012384, 2010.

Ishimoto, H., Masuda, K., Fukui, K., Shimbori, T., Inazawa, T., Tuchiyama, H., Ishii, K., and Sakurai, T.: Estimation of the refractive index of volcanic ash from satellite infrared sounder data, Remote Sens. Environ., 174, 165-180, doi:10.1016/j.rse.2015.12.009, 2016.

Key, J. R., Yang, P., Baum, B. A., and Nasiri, S. L.: Parameterization of shortwave ice cloud optical properties for various particle habits, J. Geophys. Res., 107, AAC 7-1-AAC 7-10, doi:10.1029/2001JD000742, 2002.

Kristiansen, N. I., Prata, A. J., Stohl, A., and Carn, S. A.: Stratospheric volcanic ash emissions from the 13 February 2014 Kelut eruption, Geophys. Res. Lett., 42, 588-596, doi:10.1002/2014GL062307, 2015.

Kulkarni, G., Nandasiri, M., Zelenyuk, A., Beranek, J., Madaan, N., Devaraj, A., Shutthanandan, V., Thevuthasan, S., and Varga, T.: Effects of crystallographic properties on the ice nucleation properties of volcanic ash particles, Geophys. Res. Lett., 42, 30483055, doi:10.1002/2015GL063270, 2015.
Kylling, A., Kahnert, M., Lindqvist, H., and Nousiainen, T.: Volcanic ash infrared signature: porous non-spherical ash particle shapes compared to homogeneous spherical ash particles, Atmos. Meas. Tech., 7, 919-929, doi:10.5194/amt-7-919-2014, 2014.

Lavanant, L., Fourrié, N., Gambacorta, A., Grieco, G., Heilliette, S., Hilton, F. I., Kim, M.-J., McNally, A. P., Nishihata, H., Pavelin, E. G., and Rabier, F.: Comparison of cloud products within IASI footprints for the assimilation of cloudy radiances, Q. J. Roy. Meteor. Soc., 137, 1988-2003, doi:10.1002/qj.917, 2011.

Li, J., Huang, H.-L., Liu, C.-Y., Yang, P., Schmit, T. J., Wei, H., Weisz, E., Guan, L., and Menzel, W. P.: Retrieval of cloud microphysical properties from MODIS and AIRS, J. Appl. Meteorol., 44, 1526-1543, 2005.

Maddy, E. S., King, T. S., Sun, H., Wolf, W. W., Barnet, C. D., Heidinger, A., Cheng, Z., Goldberg, M. D., Gambacorta, A., Zhang, C., and Zhang, K.: Using MetOp-A AVHRR Clear-Sky Measurements to Cloud-Clear MetOp-A IASI Column Radiances, J. Atmos. Ocean. Tech., 28, 1104-1116, doi:10.1175/JTECH-D-1005045.1, 2011

Mayer, B. and Kylling, A.: Technical note: The libRadtran software package for radiative transfer calculations - description and examples of use, Atmos. Chem. Phys., 5, 1855-1877, doi:10.5194/acp-5-1855-2005, 2005.

Newman, S. M., Clarisse, L., Hurtmans, D., Marenco, F., Johnson, B., Turnbull, K., Havemann, S., Baran, A. J., O'Sullivan, D., and Haywood, J.: A case study of observations of volcanic ash from the Eyjafjallajökull eruption: 2. Airborne and satellite radiative measurements, J. Geophys. Res., 117, D00U13, doi:10.1029/2011JD016780, 2012.

National Oceanic and Atmospheric Administration (NOAA): Comprehensive Large Array-data Stewardship System (CLASS), available at: http://www.class.ncdc.noaa.gov/saa/products/ welcome, last access: 4 May 2016.

Peyridieu, S., Chédin, A., Capelle, V., Tsamalis, C., Pierangelo, C., Armante, R., Crevoisier, C., Crépeau, L., Siméon, M., Ducos, F., and Scott, N. A.: Characterisation of dust aerosols in the infrared from IASI and comparison with PARASOL, MODIS, MISR, CALIOP, and AERONET observations, Atmos. Chem. Phys., 13, 6065-6082, doi:10.5194/acp-13-6065-2013, 2013.

Pollack, J. B., Toon, O. B., and Khare, B. N.: Optical properties of some terrestrial rocks and glasses, ICARUS, 19, 372-389, 1973.

Prata, A. J.: Infrared radiative transfer calculations for volcanic ash clouds, Geophys. Res. Lett., 16, 1293-1296, 1989.

Rose, W. I., Delene, D. J., Schneider, D. J., Bluth, G. J. S., Krueger, A. J., Sprod, I., McKee, C., Davies, H. L., and Ernst, G. G. J.: Ice in the 1994 Rabaul eruption cloud: implications for volcano hazard and atmospheric effects, Nature, 375, 477-479, doi:10.1038/375477a0, 1995.

Rose, W. I., Bluth, G. J. S., and Watson, I. M.: Ice in volcanic clouds: When and Where?, Proceedings of the 2nd International Conference on Volcanic Ash and Aviation Safety, OFCM Washington D. C., Session 3, 61, 2004.

Schlüssel, P., Hultberg, T. H., Phillips, P. L., August, T., and Calbet, X.: The operational \{IASI\} Level 2 processor, Adv. Space Res., 36, 982-988, doi:10.1016/j.asr.2005.03.008, 2005.

Snyder, W. C., Wan, Z., Zhang, Y., and Feng, Y.-Z.: Thermal Infrared (3-14 $\mu \mathrm{m})$ bidirectional reflectance measurements 
of sands and soils, Remote Sens. Environ., 60, 101-109, doi:10.1016/S0034-4257(96)00166-6, 1997.

Wang, C., Yang, P., Platnick, S., Heidinger, A. K., Baum, B. A., Greenwald, T., Zhang, Z., and Holz, R. E.: Retrieval of Ice Cloud Properties from AIRS and MODIS Observations Based on a Fast High-Spectral-Resolution Radiative Transfer Model, J. Appl. Meteorol. Clim., 52, 710-726, doi:10.1175/JAMC-D-12020.1, 2013.

Wen, S. and Rose, W. I.: Retrieval of sizes and total masses of particles in volcanic clouds using AVHRR bands 4 and 5, J. Geophys. Res., 99, 5421-5431, 1994.
Yu, T., Rose, W. I., and Prata, A. J.: Atmospheric correction for satellite-based volcanic ash mapping and retrievals using "split window" IR data from GOES and AVHRR, J. Geophys. Res.-Atmos., 107, AAC 10-1-AAC 10-19, doi:10.1029/2001JD000706, 2002.

Zhengming Wan's Group at the Institute for Computational Earth System Science (ICESS), University of California, Santa Barbara (UCSB): MODIS UCSB Emissivity Library, available at: http://www.icess.ucsb.edu/modis/EMIS/html/seawater.html, last access: 4 May 2016. 